\title{
Experimental Study on Interfacial Shear Properties of Concrete Reinforced Stone Arch Bridges
}

\author{
Zhang Miao, Zhang Fang \\ School of Civil Engineering, Southwest Jiaotong University, Chengdu, China \\ Email address: \\ swjtuzm@qq.com (Zhang Miao)
}

To cite this article:

Zhang Miao, Zhang Fang. Experimental Study on Interfacial Shear Properties of Concrete Reinforced Stone Arch Bridges. American Journal of Civil Engineering. Vol. 6, No. 4, 2018, pp. 134-140. doi: 10.11648/j.ajce.20180604.14

Received: October 12, 2018; Accepted: October 31, 2018; Published: November 8, 2018

\begin{abstract}
To investigate the shear performance of the interface between concrete and stone, the interfacial shear test of concrete - stone carried out by using the Z-type and hoop-type specimens. The effects of different bonding methods, material strength and different forms of embedded steel bars on interfacial shear properties are considered.. The experimental results show that the bonding interface between concrete and stone is the weak point of the sample, and the damage occurs on the interface. The fracture pattern of Z-type specimen is vertical crack and diagonal crack near the interface. The crack forms of the hoop type specimens are the diagonal cracks distributed on the top of concrete, vertical and oblique cracks on the sides. Within a certain range, the strength $\mathrm{g}$ of the concrete will increase the shear strength of the interface and delay the cracking of the specimen. When the strength grades of concrete were $\mathrm{C} 35, \mathrm{C} 40$ and $\mathrm{C} 45$, the shear strength of the Z-type specimen increased by $14.7 \%$ and $10.8 \%$ respectively, and the shear strength of the hoop-type specimen increased by $15.2 \%$ and $11.1 \%$ respectively. Interfacial implantable steel bar can improve the shear resistance of interface significantly, and the greater the rate of steel bar, the greater the shear strength. When the planting rates were $0 \%, 0.196 \%, 0.392 \%$ and $0.785 \%$ respectively, the improvement rates of shear strength of Z-type specimens were $40.2 \%, 65.5 \%$ and $45.2 \%$ respectively, and the improvement rates of shear strength of hoop specimens were $64.1 \%, 54.5 \%$ and $60.5 \%$ respectively. The shear strength of the hoop type specimen is greater than that of the Z-type specimen, the non-planted bar specimen is increased by about $20 \%$, and the planted steel bar specimen is increased by about $40 \%$ to $55 \%$.
\end{abstract}

Keywords: Concrete, Stone, Interface, Planting Steel Bar, Shear Strength

\section{Introduction}

Stone arch bridge has a long history in China. It is widely used in the early stage because of its beautiful shape and convenient material. After many years of use, a considerable proportion of stone arch bridges, there are low bearing capacity, structural aging and other diseases in varying degrees, cannot meet the requirements of modern traffic development and traffic safety, need to be repaired and strengthened $[1,2]$. In the method of strengthening the stone arch bridge, the method of strengthening the stone arch bridge by the method of concrete enlargement interface is widely applied [3]. Whether the interface between concrete and stone can be effectively bonded together is the key to ensure the reinforcement effect, and the shear performance of the interface is an important index to measure the mechanical properties of the interface [4].
Previous studies on the interfacial shear properties of different materials have focused on the bonding of new and old concrete. [5-8] There are few tests and theoretical studies on interfacial shear properties of concrete and stone. Existing research has focused on the application of this reinforcement technology. [9-13] In this paper, the shear behavior of concrete-stone interface and its influencing factors are studied by mechanical tests. It has important practical significance for concrete strengthening stone arch bridge, and provides scientific basis and theoretical reference for engineering application.

\section{The Experiment}

\subsection{Experimental Methods and Specimen Making}

The interfacial shear properties of concrete and stone were 
tested by Z-shear specimens and hoop shear specimens. The interface sizes are $200 \times 200 \mathrm{~mm}^{2}$ and $4 \times 200 \times 200 \mathrm{~mm}^{2}$ respectively. The design of the specimen is shown in Figure 1.
In order to prevent other parts from destroying in advance of the "shear interface", the other parts of the specimen were strengthened by reinforcement.

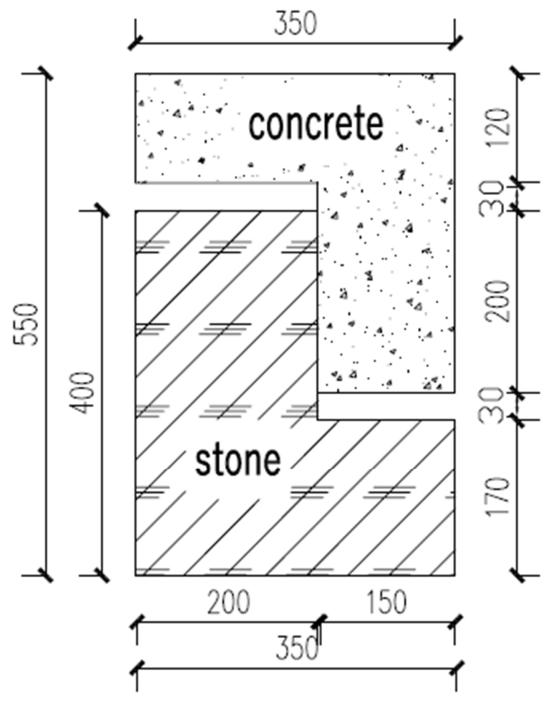

(a) Design drawing of Z-type specimen
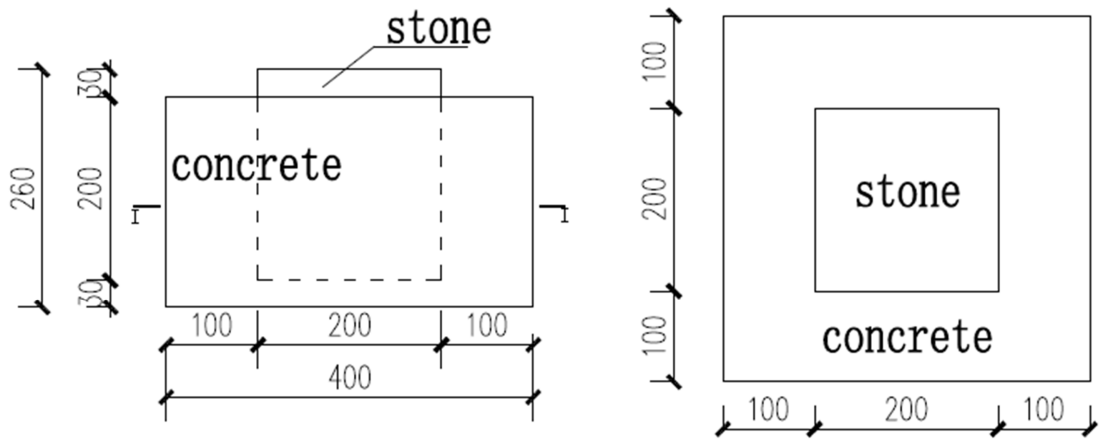

(b) Design drawing of hoop-type specimen

Figure 1. Design drawing of shear specimen.

Z-shear specimens and hoop shear specimens were divided into three groups, each group of three specimens, a total of 18 as follows:

(1) A group specimens: concrete strength grades is C35, C40 and C45 respectively, 5, and the interface is not planted.

(2) B group specimens: concrete strength grades is C35, $\mathrm{C} 40$ and $\mathrm{C} 45$ respectively, and the interface planting bar is $1 \mathrm{~B} 10$;

(3) $\mathrm{C}$ group specimens: the strength grade of concrete is $\mathrm{C} 40$, and the interface planting bar is $1 \mathrm{~B} 10,2 \mathrm{~B} 10$ and 4B10, respectively.

The stone is made of black sandstone with strength grade MU60, and the surface is treated by hand-held electric hammer. The roughness of the interface is about $2 \mathrm{~mm}$. The planting bar specimens are drilled at the place where the bar is planted. After the hole is cleaned, the anchoring adhesive is used for the planting. According to the design size, the template is made, concrete is poured, and the test is carried out after 28 days' maintenance. The specimen is shown in Figure 2.

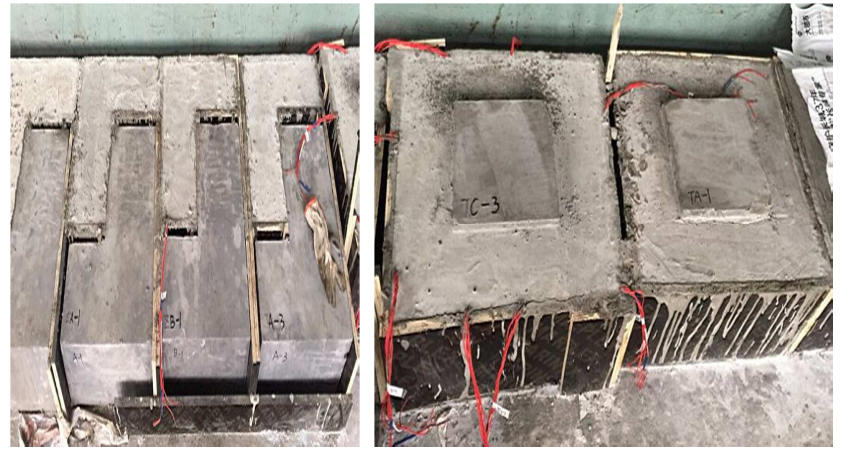

Figure 2. Specimen making.

\subsection{Loading Program and Measurement Scheme}

The shear properties of concrete and stone bonding interface was tested on $200 \mathrm{~T}$ microcomputer controlled electro-hydraulic servo pressure testing machine. The test loading process uses grading loading, and different grading loading is performed according to the estimated damage load. Before the specimen cracking, the Z-type non-planted bar 
specimens are $3 \mathrm{KN}$ per level, and the planted bar specimens are $5 \mathrm{KN}$ per level. The hoop-type non-planted bar specimens are $10 \mathrm{KN}$ per level, and the planted bar specimens are $20 \mathrm{KN}$ per level. Record the crack condition, strain and displacement data under every level loads.

Strain gauges are bonded to Z-type specimens on both sides of the bonding interface and hoop-type specimens on the upper, middle and lower surfaces of concrete. It is used to investigate the strain distribution of bonding interface. Three strain gauges are attached to each steel bar, which are placed in the stone, at the interface, and in the concrete. The strain measuring point and the test loading device are shown in Figure 3.

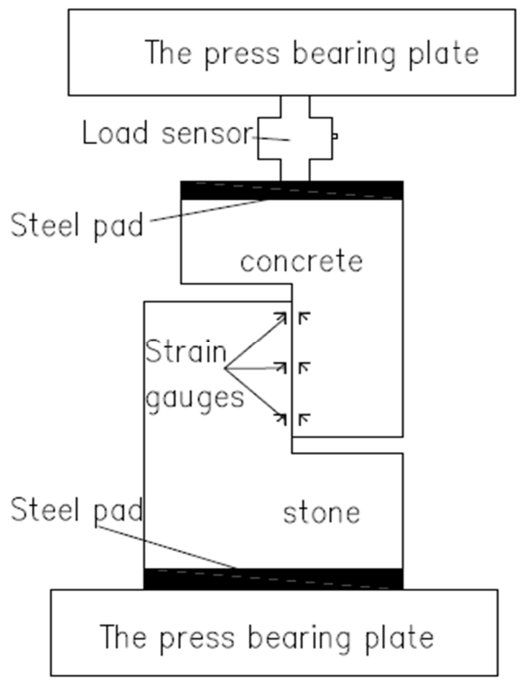

(a) Z-type specimen

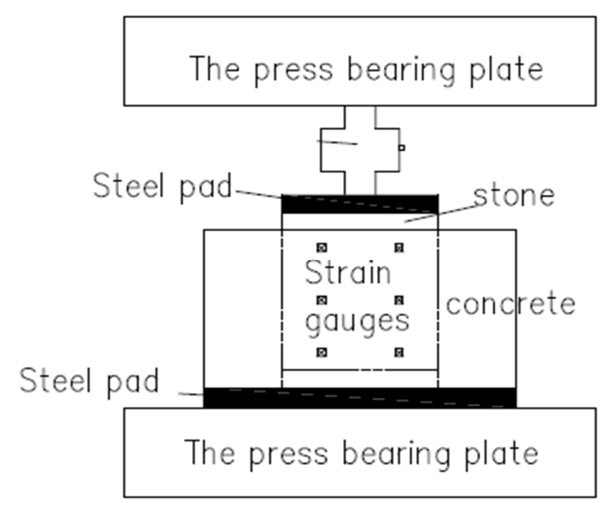

(b) hoop-type specimen

Figure 3. Strain measuring point and the test loading device.

The loading process is classified according to the magnitude of the ultimate load. Record the crack development, strain and displacement data of specimens under different loads.

\section{Results and Discussion}

\subsection{Failure Process and Morphology Analysis}

The failure of all specimens is the shear failure of the interface. Description of concrete and stone bonding interface is weak at the specimen. The fracture pattern of Z-type specimen is vertical crack and diagonal crack near the interface. As shown in figure 4. The fracture pattern of hoop type specimen, in addition to the interface, vertical and oblique cracks appear in many places such as the top surface of the concrete, the side surface and the position of the planting bar. As shown in figure 5 .
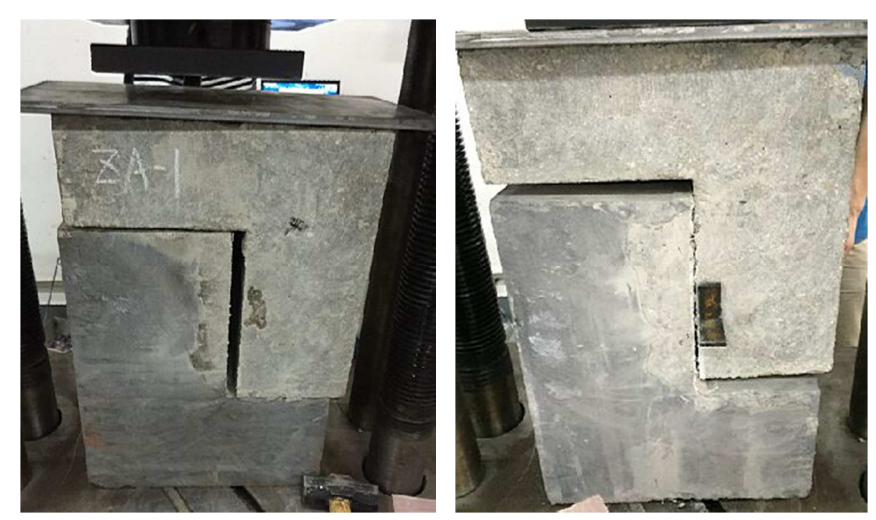

Figure 4. Fracture diagram of Z-type specimen.
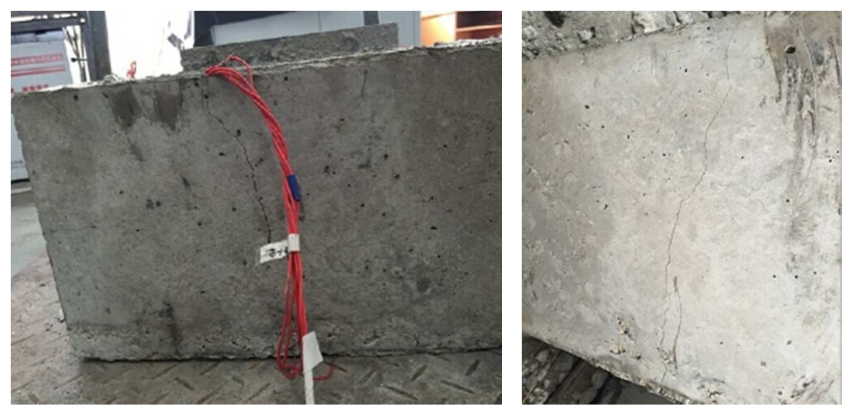

Figure 5. Fracture diagram of hoop-type specimen.

The specimens with non-planted bars quickly cracked after interface cracking. It is obvious brittle failure. The planted bar specimens after the interface cracking, the pinning action of the steel bar begins to bear the load until the specimen is destroyed. It has obvious characteristics of ductile failure.

\subsection{Distribution of Interfacial Strain}

According to the strain data collected from the test, the stress distribution of concrete and stone at the interface is not uniform. The stress change at the interface of the non-planted bar specimens decreases gradually from the middle to the bottom, and the ultimate strain at the interface is very small. The $\mathrm{Z}$ type specimen is about $40 \sim 60 \mu \varepsilon$, and the hoop type specimen is about $80 \sim 110 \mu \varepsilon$.

For planted bar specimens, reinforcement has not yet entered the work at the initial stage of loading. The interface stress distribution is similar to that of the un planted bar. After the interface cracks, the steel bar starts to work. Due to the pin of the steel bar, the stress distribution of the interface changes. The interface stress distribution decreases from the position of planting bar to the surrounding area. When the ratio of planting reinforcement was $0.196 \%, 0.392 \%$ and $0.785 \%$, the ultimate compressive strain of the concrete and 
stone of Z-type specimens was $221 \mu \varepsilon, 513 \mu \varepsilon$ and $1146 \mu \varepsilon$, respectively. The ultimate pressure strain of the hoop type specimens was $252 \mu \varepsilon, 825 \mu \varepsilon$ and $1401 \mu \varepsilon$, respectively. It can be seen that the interface planted bar can change the stress distribution at the interface between concrete and stone, and improve the shear performance of the interface.

The strain distribution of the planted steel bar is very small at the initial stage of loading. When loaded into cracking load, the strain of implanted steel bars increases sharply and shows nonlinear growth. The strain value of the steel bar at the interface is the largest and decreases gradually toward both ends, and the strain of the implanted steel bar in the stone material is less than that of the implanted steel bar in the concrete. When the specimens are destroyed, the stress of reinforcing bars approaches or reaches the yield stress at the interface, but the stress of reinforcing bars at both ends is small, far from the yield stress.

\subsection{Test Result}

The cracking load, ultimate load and shear displacement of each test piece are summarized in Table 1. The interfacial shear strength in Table 1 is calculated by formula (1).

$$
\tau=\mathrm{P}_{\mathrm{u}} / \mathrm{A}
$$

Where $\mathrm{P}_{\mathrm{u}}$ is the ultimate load of the test, Ais the interface contact area.

Table 1. The experiment results of concrete-stone interfacial shear property.

\begin{tabular}{|c|c|c|c|c|c|c|c|c|c|}
\hline $\begin{array}{l}\text { Specimen } \\
\text { No. }\end{array}$ & $\begin{array}{l}\text { Cracking load } \\
\text { Pc/KN }\end{array}$ & $\begin{array}{l}\text { Ultimate } \\
\text { load } \mathrm{Pu} / \mathrm{KN}\end{array}$ & $\begin{array}{l}\text { Shear strength } \\
\text { /MPa }\end{array}$ & $\begin{array}{l}\text { Shear } \\
\text { displacement } \\
\text { /mm }\end{array}$ & $\begin{array}{l}\text { Specimen } \\
\text { No. }\end{array}$ & $\begin{array}{l}\text { Cracking } \\
\operatorname{load} \mathrm{Pc} / \mathrm{KN}\end{array}$ & $\begin{array}{l}\text { Ultimate } \\
\text { load } \mathrm{Pu} / \mathrm{KN}\end{array}$ & $\begin{array}{l}\text { Shear } \\
\text { strength /MPa }\end{array}$ & $\begin{array}{l}\text { Shear } \\
\text { displacement } \\
\text { /mm }\end{array}$ \\
\hline ZA-1 & 39.82 & 40.75 & 0.98 & 0.074 & TA-1 & 198.76 & 202.35 & 1.21 & 0.082 \\
\hline ZA-2 & 42.78 & 44.75 & 1.13 & 0.068 & TA-2 & 224.50 & 231.38 & 1.39 & 0.098 \\
\hline ZA-3 & 49.84 & 51.26 & 1.25 & 0.090 & TA-3 & 245.32 & 254.47 & 1.53 & 0.103 \\
\hline ZB-1 & 40.72 & 54.81 & 1.35 & 0.455 & TB-1 & 292.30 & 325.90 & 1.92 & 0.483 \\
\hline ZB-3 & 53.65 & 70.81 & 1.71 & 0.517 & TB-3 & 326.59 & 419.81 & 2.51 & 0.549 \\
\hline ZC-1 & 53.65 & 70.81 & 1.71 & 0.517 & TC-1 & 326.59 & 419.81 & 2.51 & 0.549 \\
\hline ZC-2 & 56.32 & 116.03 & 2.83 & 0.904 & $\mathrm{TC}-2$ & 360.32 & 639.50 & 3.88 & 1.112 \\
\hline ZC-3 & 68.83 & 169.27 & 4.11 & 1.231 & TC-3 & 580.80 & 1020.47 & 6.23 & 1.329 \\
\hline
\end{tabular}

\subsection{Analysis of Test Results}

\subsubsection{Analysis of Interfacial Shear Mechanism}

Based on the experimental results and the theory of friction and shear [14], the interfacial shear mechanism is analyzed. Firstly, the following basic assumptions are made:

(1) The extrusion force at the interface should be equal to the pulling force of the steel bar.

(2) It is assumed that the total shear strength of the interface consists of the following three parts:

V1: Van der Waals force, chemical bonding force of concrete and mechanical bonding force caused by mutual penetration between cement and stone in concrete.

V2: Friction due to tension due to tension of steel bars;

V3: Direct shear force of planted bar.

The shear capacity of the non-planted bar specimens is mainly composed of the van der Waals force of the interface, the chemical bonding force of the concrete and the mechanical bite force caused by the mutual penetration of the cement stone. As shown in figure 6. That is:

$$
\mathrm{V}=\mathrm{V} 1 \text {. }
$$

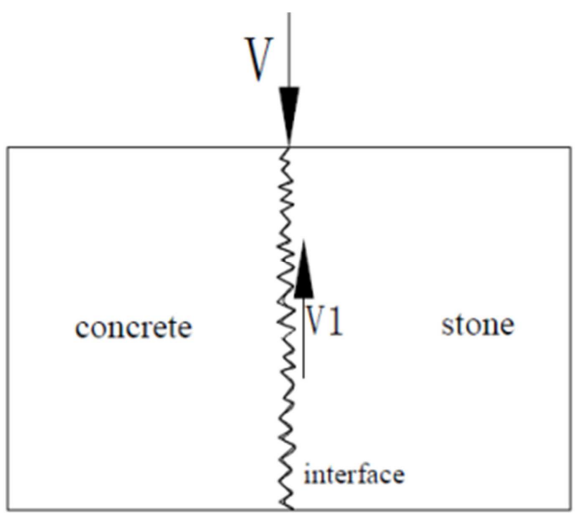

Figure 6. Force state diagram of non-planted specimen interface.

The shear failure process of the planting specimen can be divided into the following three stages:

(1) From the beginning of loading until the interface is cracked, V1 bears all the shear capacity. As shown in figure 7. That is:

$$
\mathrm{V}=\mathrm{V} 1 \text {. }
$$




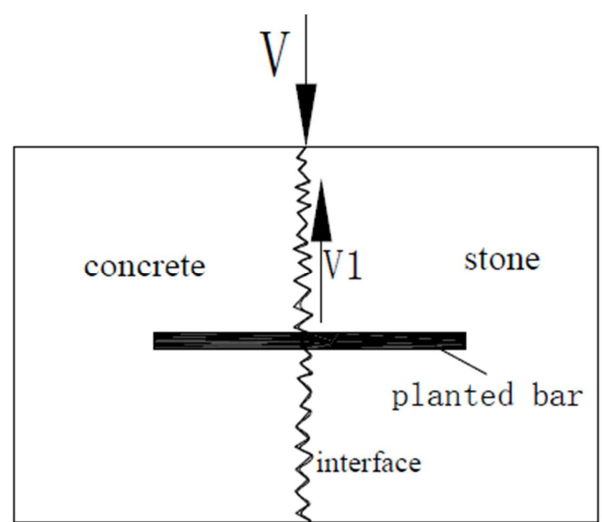

Figure 7. Force state diagram of interface before cracking.

(2) Interfacial crack development stage: The development of the crack experienced the process of initial cracking of the interface until the crack continued to develop throughout the entire interface. At this stage, the planted steel bars begin to participate significantly in the shear process of the interface. As shown in figure 8 That is,:

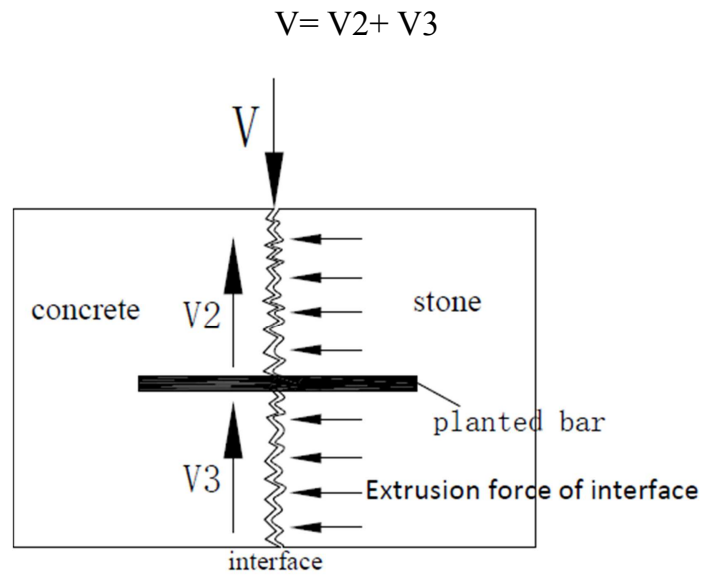

Figure 8. Force state diagram after interface cracking.

(3) Specimens destruction stage: After the interface is separated, the bite cooperation force of the interface is reduced to zero, and the pinning action of the steel bar bears all the shear capacity. As shown in figure 9. That is:

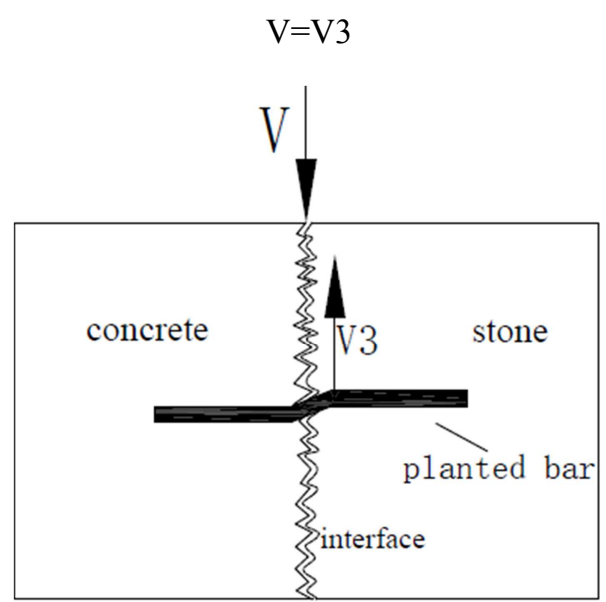

Figure 9. Force state diagram after interface separation.
The shear bearing capacity of the non-planted bar specimens is mainly caused by the bonding force of the interface, and the failure of the specimens is the "bonding failure" of the interface. For the planted specimens, after the interface between the concrete and the stone is cracked, the steel bars begin to enter the work and bear the main shear load. Therefore, the failure mode of the planting specimens is related to the failure mode of the stone planted bars.

\subsubsection{Effect of Concrete Strength on Shear Strength of Interface}

The shear strength test results show that when the strength grade of concrete increases from $\mathrm{C} 35$ to $\mathrm{C} 40$ and from $\mathrm{C} 40$ to $\mathrm{C} 45$, the increase rate of shear strength of ZA group was $15.3 \%$ and $10.6 \%$ respectively, and the improvement rate of ZB group was $14.1 \%$ and $11 \%$ respectively. The improvement rate of TA group was $15.8 \%$ and $10.8 \%$ respectively, and the improvement rate of TB group was $14.6 \%$ and $11.4 \%$ respectively. With the increase of concrete strength grade, the shear strength is also increasing, but the increase is decreasing. As shown in figure 10.

The change of concrete strength grade also has a certain effect on the shear strength of cracking. The shear strength of cracking also increases with the increase of concrete strength grade. The shear strength of z-type planted bar specimens is slightly higher than that of non-planted bar specimens due to the fact that the shear strength at the interface of z-type specimens before cracking is mainly provided by the adhesion and friction between concrete and stone. The shear strength of planted bar specimens of hoop type is much higher than that of non-planted bar specimens when they crack. This is because hoop strengthens the function of planted bar and further delays the cracking of specimens.

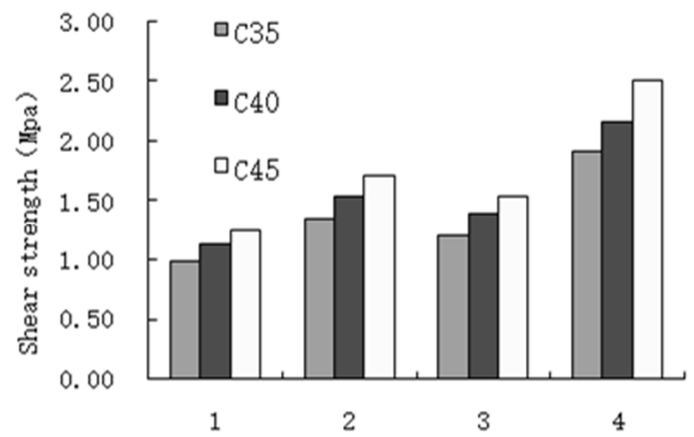

Figure 10. Influence of concrete strength grade on interfacial shear strength.

From the results of shear displacement, it can be seen that the increase of concrete strength can effectively delay the interface cracking and thus reduce the shear displacement. Firstly, the increase of concrete strength will increase the bonding force of the joint surface, thus restraining the relative slip of the shear surface. Secondly, with the increase of concrete strength, the bond and anchorage performance between concrete and steel bar is better under the same load, and the bond slip between them is smaller, which makes the shear displacement of the interface smaller.

\subsubsection{Effect of Planted Bar on Shear Strength of Interface}

The interface planted bar can effectively improve the shear 
strength of the specimen. The greater the planting rate of the interface, the greater the shear strength of the specimen. Because when the interface cracks, the shear strength at the interface of the specimen is mainly provided by the pin of the steel bar.

When the planting rate was $0 \%, 0.196 \%, 0.392 \%$ and $0.785 \%$, the increase rate of shear strength of Z-type specimens is $40.2 \%, 65.5 \%$ and $45.2 \%$ respectively, and the increase rate of hoop-type specimens is $64.1 \%, 54.5 \%$ and $60.5 \%$ respectively. As shown in figure 11 . The increase of shear strength is not linear with the increase of planting ratio, and the increase of hoop-type specimens is greater than that of Z-type specimens.

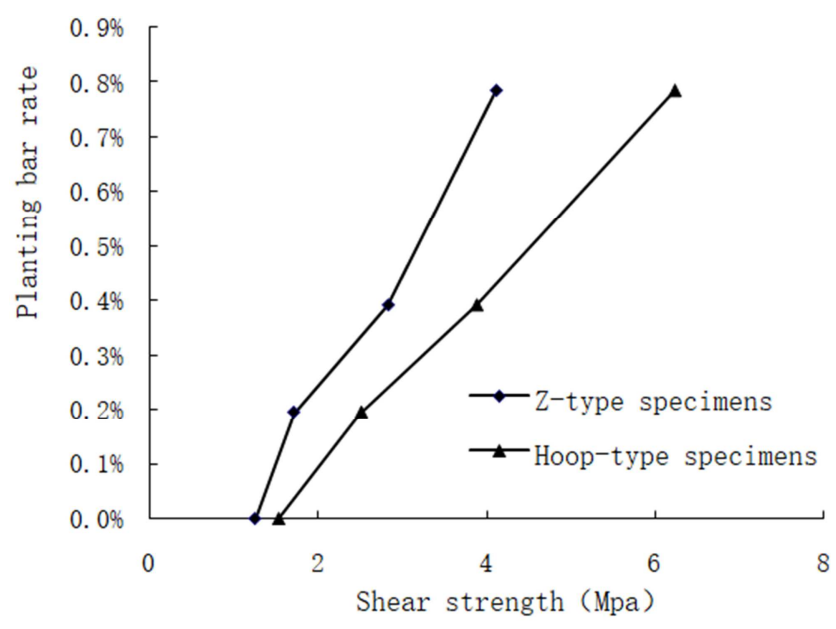

Figure 11. The relationship between the planting rate and shear strength

\subsubsection{Effect of Hoop Effect on Shear Strength of Interface}

From the data in Table 1, it can be seen that the shear strength of the hoop-type specimens is greater than that of the Z-type specimens when it cracked. This is due to the side-limiting effect of the hoop effect on the internal stone, which can increase the friction and cohesion between the two, thus delaying its cracking.

The ultimate shear displacement of the hoop type specimen is greater than that of the Z-type specimen. But under the same load, the shear displacement of the hoop specimen is smaller than that of the Z-type specimen. It shows that the core restraining effect of the hoop can effectively reduce the shear displacement of the same level load. But the ultimate shear strength of the hoop type specimen is larger than that of the $\mathrm{Z}$ type specimen, and the ultimate shear displacement value is also large.

Under the same conditions, the shear strength of the hoop specimen is greater than that of the $\mathrm{Z}$ specimen. As shown in figure 8 . The ratio of shear strength between hoop and Z-type unplanted bars is about 1.2, and that of planted bars is between 1.40 and 1.55. As shown in figure 12 .

The increase of planted steel bar specimens is greater than that of non-planted steel bar specimens. Because the hoop effect not only strengthens the bonding and friction of the interface, but also enhances the pin effect of planted steel bar.

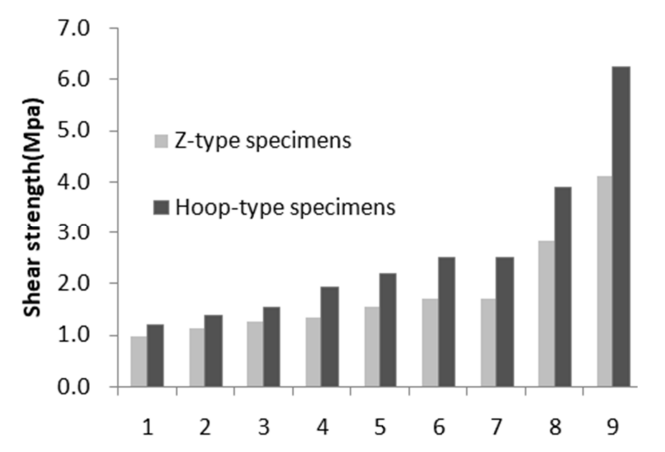

Figure 12. Z-type and hoop-type specimens' Shear strength contrast figure.

\section{Conclusion}

Through the analysis of the shear performance test results of concrete and stone bonding interface, the following conclusions can be drawn:

The interface is the weak part of the specimen, and the damage happens on the bonding interface of concrete and stone. The fracture form of Z-type specimen is vertical crack and oblique crack distributed near the interface. In addition to the interface, the crack form of the hoop type test piece also has vertical and oblique cracks distributed on the top surface and side of the concrete and the position of the planting bar. The stress distribution of concrete and stone at the interface is not uniform, and the interfacial stress change of the unreinforced specimen is gradually reduced from the upper and lower ends of the interface. Due to the pinning action of the steel bar, the stress of the planting bar will change the distribution of the interface stress, so that the stress distribution near the planting position is larger and divergent decreases toward the surrounding. The stress distribution of the steel bar is the largest near the interface and gradually decreases toward both ends.

The shear capacity of the non-planted specimens is mainly borne by the bonding force of the interface, and the failure mode of the specimen is the "bonding failure" of the interface. The shear bearing capacity of the planted specimens before the interface cracking is borne by the bonding force of the interface. After the interface is cracked until the complete separation stage, the shear bearing capacity is shared by the cohesive force, the friction force and the bolting force of the steel bar. After the interface is completely separated, the shear capacity is solely borne by the steel bars. The failure mode of the specimen is related to the failure mode of the stone planting bar.

Concrete strength has a certain effect on the shear strength of concrete and stone bonding interface. When the concrete strength grades are C35, C40 and C45, the shear strength of Z-type specimens increases by $14.7 \%$ and $10.8 \%$ respectively, and the shear strength of hoop-type specimens increases by $15.2 \%$ and $11.1 \%$ respectively. In a certain range, with the increase of concrete strength, the shear strength of the interface increases nonlinearly, which can delay the interface cracking and reduce the shear displacement of the 
interface. Planted bar can effectively improve the shear strength of the interface. When the planting rate was 0 , $0.196 \%, 0.392 \%$ and $0.785 \%$, the shear strength of Z-type specimens increased by $40.2 \%, 65.5 \%$ and $45.2 \%$ respectively, and that of hoop-type specimens increased by $64.1 \%, 54.5 \%$ and $60.5 \%$ respectively. Therefore, it is necessary to configure a certain amount and depth of planting bar at the bonding interface. Under the same conditions, the interfacial shear strength of hoop-type specimens is higher than that of Z-type specimens. Hoop effect can effectively delay the cracking of the interface between concrete and stone, reduce the shear displacement of the interface under the same load, and effectively improve the shear strength of the interface. The shear strength of unplanted bar specimens is increased by about $20 \%$, and that of the planted bar specimens is increased by $40 \%$ to $55 \%$.

\section{References}

[1] LI Jiantong. Causes Analysis of Hazards And Control Strategies Of The Spandrel-filled Stone Arch Bridge in Mountain Areas. Chongqing Jiaotong University, 2017.

[2] JIA Yue. Analysis and reinforcement of stone arch bridge. Henan: Zhengzhou University, 2013:2.

[3] Qiao Wenjing. Study on Model Test and Engineering Application of Masonry Arch-bridge Reinforced with Composite Arch Circle. Chang' an University, 2014.

[4] GAO Jian-ping, PAN Jing-long, WANG Yu-guang. Effect of different bonding agentsonbond strengthbetween fresh concrete and hardened concrete. Journal of Harbin University of C. E.\&Architecture, 2001, 34 (5):25-29.

[5] Mao Dejun, Qian Yongiiu. Calculation methods of shear strength on new-to-old concrete interface. [J]. Building Structure, 2016, 46 (15), 65-68.
[6] HUANG Lu, ZHUO Weidong, GU Yin. Effect test of interface agent on bonding of old and new concrete. Journal of Fuzhou University (Natural Soienc; e Edition), 2018, 46 (3), 396-402.

[7] WANG Zhen1ing. Study on Bond Theory and Test of New and Old Concrete and its Application in Bridge Strengthening Engineering [D]. Southwest Jiaotong University, 2006::9-10.

[8] Hu T M, Ding K X, Zhang G H, et al. Research on shear behavior of bonding interface of existing concrete structure strengthened by steel fiber reinforced self-Stressing concrete Building Structure, 2018, 48 (18), 83-87.

[9] SUN Chao, LIU Ming, CHEN Bao-chun. Research on ultimate load-carrying capacity of composite arch ring of stone arch bridge reinforced by concrete arch-lifted method [J]. 2012, 40 (3):376-382.

[10] ZHANG Jing, QIAN Yong-jiu. Theoretical Analysis of Normal Section Bearing Capacity of Stone MainArch Ring Strengthened by Reinforced Concrete [J]. Journal of Highway and Transportation Research and Development, 2008, 25 (6):76-80.

[11] LIU Qing-yang, ZHOU Jian-ting, WANG Ling, ZHU Xiao-long. Minimum Thickness of Reinforcing Layer of Stone Arch Bridge Strengthened by Section Enlargement Method [J]. Journal of Chongqing Jiaotong University (Natural Science) 2008, 27 (1):20-23.

[12] Yan Yonglun, Sun Junhai. Research on Mechanical Calculation Model of Rib-type Variable Section Clamp Reinforced Arch Bridge [J], Highway, 2008 (5) 101-103.

[13] ZHANG Miao, ZHANG Jing. Experimental StudyMasonry by Plantingon Shearing Property of Interfacial Bonding of Concrete and StoneReinforced Bar [J],. Building Science, 2015, 31 (1):43-47.

[14] BIRKELAND P W, BIRKELAND $\mathrm{H}$ W. Connections in precast concrete construction [J]. Journal of the American Concrete institute, 1966, 63 (3), 345. 